\title{
Alternative approaches to derive disability weights in injuries: do they make a difference?
}

\author{
Juanita A. Haagsma - S. Polinder · E. F. van Beeck • \\ S. Mulder · G. J. Bonsel
}

Accepted: 20 April 2009/Published online: 7 May 2009

(C) The Author(s) 2009. This article is published with open access at Springerlink.com

\begin{abstract}
Background In burden of disease studies, several approaches are used to assess disability weights, a scaling factor necessary to compute years lived with disability (YLD). The aim of this study was to quantify disability weights for injury consequences with two competing approaches, (a) standard QALY/DALY model (SQM) which derives disability weights from patient survey data and (b) the annual profile model (APM) which derives weights for the same patient data valued by a panel.

Methods Disability weights were assessed using (a) EQ5D data from a postal survey among 8,564 injury patients $2 \frac{1}{2}, 5$, and 9 months after attending the Emergency Department, and (b) preferences of 143 laymen elicited with the time trade-off method.

Results Compared with APM, SQM disability weights were consistently higher. YLD calculated with SQM disability weights was more than three times higher compared

J. A. Haagsma · G. J. Bonsel

Institute for Health Policy and Management, Erasmus Medical

Center, Erasmus University Rotterdam, Rotterdam,

The Netherlands

\section{J. A. Haagsma ( $\square)$}

Centre for Infectious Disease Control, National Institute of Public Health and the Environment, P.O. Box 1, 3720 BA, Bilthoven, The Netherlands

e-mail: juanita.haagsma@rivm.nl

J. A. Haagsma - S. Polinder · E. F. van Beeck - G. J. Bonsel Department of Public Health, Erasmus Medical Centre, Erasmus University Rotterdam, Rotterdam, The Netherlands

\section{S. Mulder}

Consumer Safety Institute, Amsterdam, The Netherlands
\end{abstract}

with YLD calculated with APM disability weights, for mild injuries with short duration, this increase was six fold.

Conclusions The APM seems the preferred method in burden of injury studies that includes mild conditions with a rapid course, since the SQM approach might overestimate the impact of the latter. The APM, however, might underestimate the impact of injury consequences, especially in case of severe injuries.

Keywords Burden of illness · Injuries ·

Quality-adjusted life years · Utility

$\begin{array}{ll}\text { Abbreviations } \\ \text { APM } & \text { Annual profile model } \\ \text { DALY } & \text { Disability adjusted life years } \\ \text { ED } & \text { Emergency department } \\ \text { EQ-5D } & \text { EuroQol-5D } \\ \text { ICD } & \text { International statistical classification of disease, } \\ & \text { Injuries and causes of death } \\ \text { QALY } & \text { Quality adjusted life years } \\ \text { SQM } & \text { Standard QALY/DALY model } \\ \text { TTO } & \text { Time trade-off technique } \\ \text { YLD } & \text { Years lived with disability } \\ \text { YLL } & \text { Years of life lost } \\ \text { VAS } & \text { Visual analogue scale }\end{array}$

Background

Since the application of the concept in 1993, the Disability Adjusted Life Year (DALY) is used increasingly for priority setting in health care and prevention [1]. The DALY is a health gap measure that aggregates mortality and morbidity data, thus allowing comparison of population health status between countries as well as comparison 
between diseases within a country [2]. To aggregate mortality and morbidity data, years of life lost due to premature mortality (YLL) and years lived with disability (YLD) have to be established. Essential for the latter is the disability weight; a scaling factor that expresses the impact of a disease with a value ranging from 0 , indicating the best possible health state, through 1 , indicating worst possible health state [3]. By multiplying the disability weight of a condition by its incidence and its average duration (or prevalence in case of chronic disease), the healthy time lost due to living with disability (YLD) is calculated.

Regarding disability weights, there are two dominant approaches, both have been used in burden of disease studies. One of these approaches is to adopt existing disability weights from the Global Burden of Disease study [4]. In order to compute YLD, the GBD disability weights are then applied using the standard QALY/DALY model (SQM). The SQM assumes independence between duration and disability and it requires that the health state remains fixed over time [5-7]. For health states with dynamic and/ or complex patterns this assumption is untenable, since these health states in fact have to be separated into numerous parts.

A field abundant of dynamic recovery patterns with a wide variation in duration is the field of injuries. Moreover, the existing set of disability weights as published by Murray et al. [4] lacks a number of highly incident nonignorable long-term injury consequences, which ultimately results in an underestimation of the total burden of injury. To address both the issue of complexity over time and the issue of incomplete coverage of long-term sequelae, existing methods have to be adapted or extended. At this stage, the SQM approach has been administered to several burden of injury studies [8-11]. This approach uses a twostep procedure to assign disability weights to health outcomes. Firstly, patients report their own health state using one of the available generic health state classification systems. These classification systems render the health state of an individual by the function level that he/she reports on each of the domains. The weight of that health state is computed by a formula that firstly yields a partial weight score for each domain depending on the reported level, and subsequently adds partial weights which by definition fit within the $0.0-1.0$ range. The partial weights of the formula, the tariff weights, are derived at an earlier stage from preference data of the population [12]. The three most commonly used systems are the EuroQol-5D (EQ-5D), the Health Utility Index, and the Quality of Well-Being Scale [13-15].

An alternative method used in burden of disease and injury studies is to obtain disability weights directly using the annual profile model (APM) $[16,17]$. Unlike the SQM, the APM describes the course of the condition over 1-year time, allowing assessment of disability weights for health states characterized by an acute onset and complex patterns of recovery. The measurement techniques to elicit the preference weights are, however, identical [16].

The aims of this study were to quantify differences between (a) disability weights for injury consequences derived from patient reported EQ-5D classification data using the SQM and (b) disability weights derived with panel elicitation using the APM, and subsequently compare YLD estimations calculated with both sets of disability weights given similar incidence data. Based on this comparison, we aimed to decide on the preference of APM above SQM in injuries.

\section{Methods}

For the selection of the injury consequences, the EUROCOST injury classification was used [18]. This classification is compatible to the International Statistical Classification of Disease, Injuries, and Causes of Death — ninth and tenth revision (ICD-9 and 10) classification system.

For assessment of the SQM and APM disability weights, data from two studies were used (1) the EQ-5D that was included in a questionnaire held among injury patients who attended the Emergency Department (ED) [9] and (2) health state valuations derived with APM panel elicitation using the visual analogue scale (VAS) and time trade-off (TTO) technique [17].

\section{SQM disability weights}

A sample of 8,564 injury patients aged 15 years and older was sent a postal questionnaire $2 \frac{1}{2}$ months after they attended the ED of a hospital in The Netherlands [9]. At 5 and 9 months, a follow-up questionnaire was sent to patients that responded to the preceding questionnaire. The sustained injuries varied from minor to severe and the sample included hospitalized and non-hospitalized patients. The sample of patients was stratified, over sampling patients with severe injuries. To measure functional outcome after injury, the questionnaires included the EQ-5D and the VAS. With the EQ-5D classification system, subjects describe their health in three levels of severity in the dimensions mobility, self-care, usual activities, pain/ discomfort, and anxiety/depression [19]. Subsequently, the reported health states were converted into utility scores using a pre-existing set of preference weights based on preference data from the general population of The Netherlands [20]. To adjust the data for non-response, a non-response analysis was performed by multivariate logistic regression, testing variables age, sex, type of injury, external cause of the injury, hospitalization and 
length of stay, health status, and ambulance transport as possible determinants of non-response. The significant variables $(P<0.05)$ were used to yield non-response weights for the sample of patients treated at the ED. Additionally, the data were adjusted for stratification of the sample of ED patients [9]. The resulting weighted data can be considered representative for an ED population of injury patients in The Netherlands. We used the weighted data to calculate the EQ-5D utility scores and included only patients who filled out all three questionnaires. For the subsequent calculation of the EQ-5D disability weights, we used the population health index of the population of the United Kingdom, adjusted for age and sex [21]. In order to determine the SQM disability weights per injury group over 1-year time, the resulting 21/2-month (T1), 5-month (T2), and 9-month (T3) disability weights were aggregated with the following formula: (T1 weight $+\mathrm{T} 2$ weight $+\mathrm{T} 3$ weight)/3. This formula was also used to calculate the aggregated VAS values per injury group over 1-year time.

\section{APM disability weights}

The APM disability weights were derived using the Dutch Disability Weights protocol with two noted modifications [22]. Firstly, a population panel rather than a panel of medical experts provided the values. The population panel ( $n=143)$ was randomly selected from an existing panel of 560 people that was recruited from the general public through an advertisement in a free newspaper that is available throughout The Netherlands. Secondly, the VAS and the TTO preference measurement methods were used to value a number of injury related health states. The VAS valuation technique requires participants to score the disease stage on a vertical thermometer graded from 0 (worst possible health state) to 100 (worst possible health state). The TTO asks participants how many days of 1 year in full health, they are willing to trade in order to be restored from the presented disease stage. Similarly to the Dutch Disability Weights study, the health states were described on a standardized 210 by $297 \mathrm{~mm}$ (A4) sized vignette which contained disease specific information in laymen terminology, a generic EQ-5D profile of the health state and an annual profile. This annual profile describes the course of the health state-the disability profile-over 1-year time, allowing assessment of diseases and injuries with a rapid course and/or complex recovery patterns [16]. Additionally, information on the location of the injury and physical alterations caused by the health state was provided. To enhance information processing, we used graphics and colors in the description and we intensively explained the health state descriptions during the panel session. Each participant valued 32 health states, 10 health states during a $3 \mathrm{~h}$ panel session and subsequently 22 health states in a questionnaire, they received at home. The order of the presented health states was randomized.

Analysis

The questionnaire rendered SQM disability weights for 32 injury groups. For 11 of these injury groups, no matching APM disability weights were available. Hence, 21 injury groups were included in the comparison between SQM and APM disability weights. For each injury group absolute difference between SQM and APM disability weights as well as SQM/APM disability weight ratio was calculated. A regression analysis was performed to determine if age and sex had significant effects on APM disability weights. The 21 injury groups were categorized into three severity classes. These injury severity classes were grouped post hoc according to the calculated APM disability weights as previously tested by an international expert group [23]. Three injury severity classes were distinguished: mild, moderate, and severe, using 0.03 and 0.10 as cut-off points. Differences between SQM and APM and ratios were calculated by injury severity class. Per injury severity class, YLDs were computed with both SQM and APM disability weights to compare the proportion YLDs lost due to mild, moderate, and severe injury consequences. To calculate YLDs lost in the first year after the injury, the incidence data (year 2002) derived from the Dutch Injury Surveillance system were used. The Dutch Injury Surveillance system is a permanent registry of injury victims treated at the Emergency Department of 15 hospitals in The Netherlands [24]. The Spearman's rank correlation coefficient was calculated to test if the SQM and APM ranking based on the mean disability weights of the 21 injury consequences were associated. The Pearson correlation coefficient was used to test whether the distributions of the SQM and APM disability weights assigned to the injury consequences were correlated.

\section{Results}

\section{Respondents}

Of the 1,392 injury patients that completed the patient surveys $2 \frac{1}{2}, 5$, and 9 months after attending the ED 53\% were male and mean age was 43 years old. The panel study was attended by 143 lay persons. Of these lay persons, 59 (41\%) were male and mean age was 48 years old.

Comparison of SQM and APM disability weights

Table 1 shows that the patient reported $2 \frac{1}{2} 2$-month disability weights were the highest and the 9-month disability 
Table 1 Disability weights derived with the standard QALY/DALY model (SQM) at 2⿺辶⿸厃 (T1), 5 (T2), and 9 (T3) months follow-up, per injury group

\begin{tabular}{|c|c|c|c|c|c|c|}
\hline \multirow[t]{2}{*}{ Injury group } & \multicolumn{2}{|l|}{$\mathrm{T} 1$} & \multicolumn{2}{|l|}{$\mathrm{T} 2$} & \multicolumn{2}{|l|}{$\mathrm{T} 3$} \\
\hline & $\mathrm{DW}^{\mathrm{a}}$ & $\mathrm{SD}^{\mathrm{b}}$ & $\mathrm{DW}^{\mathrm{a}}$ & $\mathrm{SD}^{\mathrm{b}}$ & $\mathrm{DW}^{\mathrm{a}}$ & $\mathrm{SD}^{\mathrm{b}}$ \\
\hline \multicolumn{7}{|l|}{ Head injury } \\
\hline Concussion & 0.14 & 0.22 & 0.08 & 0.19 & 0.04 & 0.11 \\
\hline Eye injury & 0.02 & 0.06 & 0.05 & 0.15 & 0.01 & 0.0 \\
\hline Fracture facial bones & 0.06 & 0.09 & 0.06 & 0.12 & 0.01 & 0.0 \\
\hline \multicolumn{7}{|c|}{ Injury of spinal cord/thorax/pelvis } \\
\hline $\begin{array}{l}\text { Fract/disl/spr/str vertebral } \\
\text { column }\end{array}$ & 0.21 & 0.21 & 0.13 & 0.18 & 0.10 & 0. \\
\hline Spinal cord injury & 0.53 & 0.23 & 0.58 & 0.28 & 0.54 & 0.45 \\
\hline Fracture rib/sternum & 0.11 & 0.20 & 0.09 & 0.16 & 0.08 & 0.18 \\
\hline Fracture pelvis & 0.19 & 0.20 & 0.14 & 0.18 & 0.16 & 0.1 \\
\hline \multicolumn{7}{|l|}{ Injury of upper extremity } \\
\hline Fracture clavicula/scapula & 0.11 & 0.14 & 0.03 & 0.08 & 0.02 & 0.08 \\
\hline Fracture elbow/fore arm & 0.15 & 0.16 & 0.02 & 0.06 & 0.03 & 0.07 \\
\hline Fracture wrist & 0.09 & 0.14 & 0.05 & 0.13 & $<0.01$ & 0.03 \\
\hline Fracture hand/fingers & 0.12 & 0.15 & 0.07 & 0.16 & 0.07 & 0.21 \\
\hline $\begin{array}{l}\text { Disl/sprain/strain shoulder/ } \\
\text { elbow }\end{array}$ & 0.12 & 0.13 & 0.05 & 0.10 & 0.04 & 0.09 \\
\hline $\begin{array}{l}\text { Disl/sprain/strain wrist/hand/ } \\
\text { fingers }\end{array}$ & 0.09 & 0.19 & 0.05 & 0.16 & 0.03 & 0. \\
\hline \multicolumn{7}{|l|}{ Injury of lower extremity } \\
\hline Fracture hip & 0.29 & 0.30 & 0.22 & 0.26 & 0.18 & 0.28 \\
\hline Fracture knee/lower leg & 0.24 & 0.21 & 0.11 & 0.17 & 0.07 & 0.1 \\
\hline Fracture ankle & 0.16 & 0.18 & 0.08 & 0.13 & 0.06 & 0.11 \\
\hline Fracture foot/toes & 0.06 & 0.11 & 0.04 & 0.09 & 0.03 & 0.07 \\
\hline Disl/sprain/strain ankle/foot & 0.12 & 0.13 & 0.07 & 0.13 & 0.09 & 0.1 \\
\hline Disl/sprain/strain hip & 0.22 & 0.23 & 0.13 & 0.21 & 0.15 & 0.2 \\
\hline \multicolumn{7}{|l|}{ External injury } \\
\hline Superficial injury & 0.12 & 0.19 & 0.07 & 0.16 & 0.05 & 0.15 \\
\hline Open wound & 0.07 & 0.11 & 0.02 & 0.07 & 0.01 & 0.02 \\
\hline
\end{tabular}

$\mathrm{SQM}=$ disability weight derived from patient reported EQ-5D data, adjusted for age and sex

${ }^{\mathrm{a}} \mathrm{DW}=$ disability weights; $0=$ full health; $1=$ worst possible health state

${ }^{\text {b }} \mathrm{SD}=$ standard deviation

weights were the lowest for all injury groups except spinal cord injury. With both SQM and APM disability weights, 0 indicates the best possible health state and 1 indicates worst possible health state.

The mean SQM and APM disability weights are presented in Table 2. The mean SQM disability weights ranged from 0.03 (eye injury and open wound) to 0.55 (spinal cord injury). The mean APM disability weights ranged from 0.002 (eye injury) to 0.57 (spinal cord injury). For 19 of the total 21 injury consequences, mean SQM disability weights were higher compared with APM disability weights, the difference ranging from 0.004 (fracture
Table 2 Disability weights derived with the standard QALY/DALY model (SQM) and the annual profile model (APM), per injury group

\begin{tabular}{|c|c|c|c|}
\hline Injury group & $\mathrm{SQM}^{\mathrm{a}}$ & $\mathrm{APM}^{\mathrm{b}}$ & $\Delta^{\mathrm{e}}$ \\
\hline & $\mathrm{DW}^{\mathrm{c}} \quad \mathrm{SD}^{\mathrm{d}}$ & $\mathrm{DW}^{\mathrm{c}} \quad \mathrm{SD}^{\mathrm{d}}$ & \\
\hline
\end{tabular}

Head injury

Concussion

$\begin{array}{llllll}0.088 & 0.13 & 0.015 & 0.02 & 0.07 & 5.9\end{array}$

Eye injury

$\begin{array}{llllll}0.027 & 0.06 & 0.002 & 0.01 & 0.02 & 13.4\end{array}$

Fracture facial bones

$\begin{array}{llllll}0.041 & 0.06 & 0.018 & 0.04 & 0.02 & 2.3\end{array}$

Injury of spinal cord/thorax/pelvis

Fract/disl/spr/str vertebral $\quad \begin{array}{lllllll}0.147 & 0.14 & 0.108 & 0.17 & 0.04 & 1.4\end{array}$ column

Spinal cord injury

$\begin{array}{llllll}0.551 & 0.29 & 0.567 & 0.32 & 0.02 & 1.0\end{array}$

Fracture rib/sternum

$\begin{array}{llllll}0.092 & 0.17 & 0.045 & 0.04 & 0.05 & 2.0\end{array}$

Fracture pelvis

$\begin{array}{llllll}0.155 & 0.15 & 0.150 & 0.13 & 0.01 & 1.0\end{array}$

Injury of upper extremity

$\begin{array}{lllllll}\text { Fracture clavicula/scapula } & 0.054 & 0.09 & 0.050 & 0.07 & <0.01 & 1.1\end{array}$

$\begin{array}{llllllll}\text { Fracture elbow/fore arm } & 0.065 & 0.07 & 0.031 & 0.06 & 0.03 & 2.1\end{array}$

$\begin{array}{llllllll}\text { Fracture wrist } & 0.047 & 0.07 & 0.054 & 0.11 & 0.01 & 0.9\end{array}$

$\begin{array}{llllllll}\text { Fracture hand/fingers } & 0.086 & 0.16 & 0.016 & 0.05 & 0.07 & 5.4\end{array}$

$\begin{array}{llllllll}\text { Disl/sprain/strain shoulder/ } & 0.073 & 0.08 & 0.036 & 0.06 & 0.04 & 2.0\end{array}$ elbow

Disl/sprain/strain wrist/ $\quad \begin{array}{lllllll}0.057 & 0.15 & 0.027 & 0.05 & 0.03 & 2.1\end{array}$ hand/fingers

Injury of lower extremity

Fracture hip

$\begin{array}{llllll}0.231 & 0.27 & 0.202 & 0.17 & 0.03 & 1.1\end{array}$

$\begin{array}{llllllll}\text { Fracture knee/lower leg } & 0.139 & 0.15 & 0.049 & 0.09 & 0.09 & 2.8\end{array}$

$\begin{array}{lllllll}\text { Fracture ankle } & 0.102 & 0.11 & 0.056 & 0.08 & 0.05 & 1.8\end{array}$

$\begin{array}{lllllll}\text { Fracture foot/toes } & 0.044 & 0.08 & 0.014 & 0.02 & 0.03 & 3.1\end{array}$

Disl/sprain/strain ankle/foot $0.093 \quad 0.13 \quad 0.026 \quad 0.03 \quad 0.07 \quad 3.6$

Disl/sprain/strain hip $\quad \begin{array}{llllllll}0.166 & 0.19 & 0.072 & 0.08 & 0.09 & 2.3\end{array}$

External injury

$\begin{array}{lllllll}\text { Superficial injury } & 0.079 & 0.15 & 0.006 & 0.01 & 0.07 & 13.2\end{array}$

$\begin{array}{lllllll}\text { Open wound } & 0.032 & 0.06 & 0.013 & 0.01 & 0.02 & 2.5\end{array}$

${ }^{a} \mathrm{SQM}=$ disability weight derived from patient reported EQ-5D data, adjusted for age and sex

b $\mathrm{APM}=$ disability weight derived from panel elicitation using the annual profile approach

${ }^{\mathrm{c}}$ DW $=$ disability weight; $0=$ full health; $1=$ worst possible health state

${ }^{\mathrm{d}} \mathrm{SD}=$ standard deviation

e $\Delta=$ absolute difference between SQM and APM disability weights

clavicula/scapula) to 0.09 (dislocation/sprain/strain hip and fracture knee/lower leg), with a mean difference of 0.04 .

The mean SQM disability weights for eye injury and superficial injury were both thirteen times higher than the AMP disability weights. For the two injury groups concussion and fracture of hand/fingers, the SQM disability weights were more than 5 times higher.

Table 3 shows that the largest absolute differences and SQM/APM disability weights ratio were found for mild injuries (mean difference of 0.05 , mean ratio of 4 ). 
Table 3 Disability weights derived with the standard QALY/DALY model (SQM) and the annual profile model (APM), per severity class

\begin{tabular}{lllll}
\hline Injury severity class & $\mathrm{SQM}^{\mathrm{a}}$ & $\mathrm{APM}^{\mathrm{b}}$ & $\Delta^{\mathrm{c}}$ & Ratio \\
\hline Mild (APM disability weight $<0.03$ ) & 0.061 & 0.015 & 0.05 & 4.0 \\
Moderate (APM disability weight & 0.092 & 0.049 & 0.04 & 1.9 \\
$\quad \begin{array}{l}\text { 0.03-0.10) } \\
\text { Severe (APM disability weight }>0.10)\end{array}$ & 0.271 & 0.257 & 0.01 & 1.1
\end{tabular}

${ }^{a} \mathrm{SQM}=$ derived from patient reported EQ-5D data, adjusted for age and sex

b $\mathrm{APM}=$ derived from panel elicitation using the annual profile approach

c $\Delta=$ absolute difference between SQM and APM disability weights

Correlation coefficients between SQM and APM disability weights were high, Pearson's correlation coefficient was 0.93 and Spearman correlation coefficient was 0.65 . No significant effects of age and sex on the TTO values were shown.

\section{Comparison of VAS values}

In Table 4, the mean VAS values derived from the injury patients and the population panel are presented. The VAS values were the lowest for eye injury (injury patients 0.12 ; population panel 0.07 ) and the highest for spinal cord injury (injury patients 0.59 ; population panel 0.87 ). Except for injury groups eye injury, dislocation/sprain/strain ankle/ foot, and superficial injury, the patient reported VAS values were lower compared with the mean VAS values of the corresponding injury groups derived from the population panel, with a mean difference of 0.09. Pearson's correlation coefficient between mean SQM and APM VAS values was 0.90 and Spearman correlation coefficient was 0.75 .

\section{Comparison of YLD estimations}

Table 5 shows the YLD estimations calculated with (a) the set of SQM disability weights and (b) the set of APM disability weights.

Application of the APM disability weights resulted in 16,947 YLDs lost, whereas application of the SQM disability weights resulted in 54,159 YLDs lost, an increase of $320 \%$ compared with the YLD estimation with APM disability weights.

With SQM disability weights, most YLDs were lost due to superficial injury $(23,219 \mathrm{YLDs})$ and dislocation/sprain/ strain of ankle and foot (4,543 YLDs). Together these two injury consequences accounted for $51 \%$ of the YLDs lost. This in contrast to the YLD estimation calculated with APM disability weights, where superficial injury $(1,763$ YLDs) and dislocation/sprain/strain of ankle and foot (1,270 YLDs) together accounted for only 18\% of YLDs
Table 4 Mean SQM VAS values reported by injury patients and mean APM VAS values derived from the population panel, per injury group

\begin{tabular}{|c|c|c|c|c|c|c|}
\hline \multirow[t]{2}{*}{ Injury group } & \multicolumn{2}{|l|}{$\mathrm{SQM}^{\mathrm{a}}$} & \multicolumn{2}{|l|}{$\mathrm{APM}^{\mathrm{b}}$} & \multirow[t]{2}{*}{$\Delta^{\mathrm{e}}$} & \multirow[t]{2}{*}{ Ratio } \\
\hline & $\mathrm{VAS}^{\mathrm{c}}$ & $\mathrm{SD}^{\mathrm{d}}$ & $\mathrm{VAS}^{\mathrm{c}}$ & $\mathrm{SD}^{\mathrm{d}}$ & & \\
\hline \multicolumn{7}{|l|}{ Head injury } \\
\hline Concussion & 0.17 & 0.16 & 0.20 & 0.12 & 0.03 & 0.9 \\
\hline Eye injury & 0.12 & 0.09 & 0.07 & 0.11 & 0.05 & 1.7 \\
\hline Fracture facial bones & 0.18 & 0.11 & 0.20 & 0.13 & 0.02 & 0.9 \\
\hline \multicolumn{7}{|c|}{ Injury of spinal cord/thorax/pelvis } \\
\hline $\begin{array}{l}\text { Fract/dis1/spr/str vertebral } \\
\text { column }\end{array}$ & 0.33 & 0.17 & 0.38 & 0.17 & 0.05 & 0.9 \\
\hline Spinal cord injury & 0.59 & 0.20 & 0.87 & 0.11 & 0.28 & 0.8 \\
\hline Fracture rib/sternum & 0.22 & 0.14 & 0.29 & 0.13 & 0.07 & 0.8 \\
\hline Fracture pelvis & 0.36 & 0.14 & 0.50 & 0.10 & 0.14 & 0.7 \\
\hline \multicolumn{7}{|l|}{ Injury of upper extremity } \\
\hline Fracture clavicula/scapula & 0.15 & 0.15 & 0.28 & 0.11 & 0.13 & 0.5 \\
\hline Fracture elbow/fore arm & 0.14 & 0.14 & 0.25 & 0.09 & 0.11 & 0.6 \\
\hline Fracture wrist & 0.12 & 0.12 & 0.30 & 0.12 & 0.18 & 0.4 \\
\hline Fracture hand/fingers & 0.14 & 0.13 & 0.16 & 0.11 & 0.02 & 0.9 \\
\hline $\begin{array}{l}\text { Disl/sprain/strain shoulder/ } \\
\text { elbow }\end{array}$ & 0.18 & 0.15 & 0.29 & 0.11 & 0.11 & 0.6 \\
\hline $\begin{array}{l}\text { Disl/sprain/strain wrist/hand/ } \\
\text { fingers }\end{array}$ & 0.15 & 0.13 & 0.23 & 0.12 & 0.08 & 0.7 \\
\hline \multicolumn{7}{|l|}{ Injury of lower extremity } \\
\hline Fracture hip & 0.41 & 0.20 & 0.46 & 0.13 & 0.05 & 0.9 \\
\hline Fracture knee/lower leg & 0.22 & 0.17 & 0.34 & 0.14 & 0.12 & 0.6 \\
\hline Fracture ankle & 0.21 & 0.17 & 0.34 & 0.13 & 0.13 & 0.6 \\
\hline Fracture foot/toes & 0.14 & 0.10 & 0.18 & 0.08 & 0.04 & 0.8 \\
\hline Disl/sprain/strain ankle/foot & 0.21 & 0.18 & 0.19 & 0.10 & 0.02 & 1.1 \\
\hline Disl/sprain/strain hip & 0.32 & 0.19 & 0.39 & 0.12 & 0.07 & 0.8 \\
\hline \multicolumn{7}{|l|}{ External injury } \\
\hline Superficial injury & 0.21 & 0.17 & 0.09 & 0.07 & 0.12 & 2.3 \\
\hline Open wound & 0.12 & 0.13 & 0.14 & 0.13 & 0.02 & 0.9 \\
\hline
\end{tabular}

${ }^{\text {a }} \mathrm{SQM}=$ VAS value derived from patient reported EQ-5D data

b $\mathrm{APM}=$ VAS value derived from panel elicitation using the annual profile approach

c VAS = VAS value; $0=$ full health; $1=$ worst possible health state

${ }^{\mathrm{d}} \mathrm{SD}=$ standard deviation

e $\Delta=$ absolute difference between SQM and APM disability weights

lost. With the APM disability weights, most YLDs were lost due to hip fracture (3,140 YLDs), contributing 19\% of YLDs lost.

As shown in Fig. 1, with the application of SQM disability weights, the majority $(72 \%, 38,920$ YLDs) of the total number of YLDs were lost due to mild injuries with a rapid course. With the APM disability weights $36 \%(6,112$ YLDs) of the total number of YLDs were lost due to mild injuries. 
Table 5 Incidence and YLD estimations calculated with standard QALY/DALY model (SQM) and annual profile model (APM) disability weights, per injury group a $\mathrm{SQM}=$ YLD calculated with disability weights derived from patient reported EQ-5D data, adjusted for age and sex

b $\mathrm{APM}=$ YLD calculated with disability weights derived from panel elicitation using the annual profile approach

\begin{tabular}{|c|c|c|c|c|c|}
\hline \multirow[t]{2}{*}{ Injury group } & \multirow[t]{2}{*}{ Incidence } & \multicolumn{2}{|l|}{$\mathrm{SQM}^{\mathrm{a}}$} & \multicolumn{2}{|l|}{$\mathrm{APM}^{\mathrm{b}}$} \\
\hline & & YLD & $\%$ & YLD & $\%$ \\
\hline \multicolumn{6}{|l|}{ Head injury } \\
\hline Concussion & 15,000 & 1,349 & 2.5 & 230 & 1.4 \\
\hline Eye injury & 25,000 & 687 & 1.3 & 51 & 0.3 \\
\hline Fracture facial bones & 7,400 & 303 & 0.6 & 133 & 0.8 \\
\hline \multicolumn{6}{|l|}{ Injury of spinal cord/thorax/pelvis } \\
\hline Fractures/disl/spr/str vertebral column & 4,400 & 650 & 1.2 & 477 & 2.8 \\
\hline Spinal cord injury & 460 & 256 & 0.5 & 264 & 1.6 \\
\hline Fracture rib/sternum & 5,000 & 463 & 0.9 & 227 & 1.3 \\
\hline Fracture pelvis & 3,200 & 499 & 0.9 & 483 & 2.8 \\
\hline \multicolumn{6}{|l|}{ Injury of upper extremity } \\
\hline Fracture clavicula/scapula & 16,000 & 869 & 1.6 & 804 & 4.7 \\
\hline Fracture elbow/forearm & 27,000 & 1,727 & 3.2 & 824 & 4.9 \\
\hline Fracture wrist & 41,000 & 1,926 & 3.6 & 2,213 & 13.1 \\
\hline Fracture hand/fingers & 45,000 & 3,881 & 7.2 & 722 & 4.3 \\
\hline Disl/sprain/strain shoulder/elbow & 15,000 & 1,095 & 2.0 & 540 & 3.2 \\
\hline Disl/sprain/strain wrist/hand/fingers & 12,000 & 704 & 1.3 & 334 & 2.0 \\
\hline \multicolumn{6}{|l|}{ Injury of lower extremity } \\
\hline Fracture hip & 16,000 & 3,591 & 6.6 & 3,140 & 18.5 \\
\hline Fracture knee/lower leg & 13,000 & 1,857 & 3.4 & 654 & 3.9 \\
\hline Fracture ankle & 18,000 & 1,814 & 3.3 & 996 & 5.9 \\
\hline Fracture foot/toes & 29,000 & 1,261 & 2.3 & 401 & 2.4 \\
\hline Disl/sprain/strain ankle/foot & 49,000 & 4,543 & 8.4 & 1,270 & 7.5 \\
\hline Disl/sprain hip & 3,000 & 492 & 0.9 & 213 & 1.3 \\
\hline \multicolumn{6}{|l|}{ External injury } \\
\hline Superficial injury & 290,000 & 23,219 & 42.9 & 1,763 & 10.4 \\
\hline Open wound & 93,000 & 2,972 & 5.5 & 1,207 & 7.1 \\
\hline Total & 730,000 & 54,159 & 100 & 16,947 & 100 \\
\hline
\end{tabular}

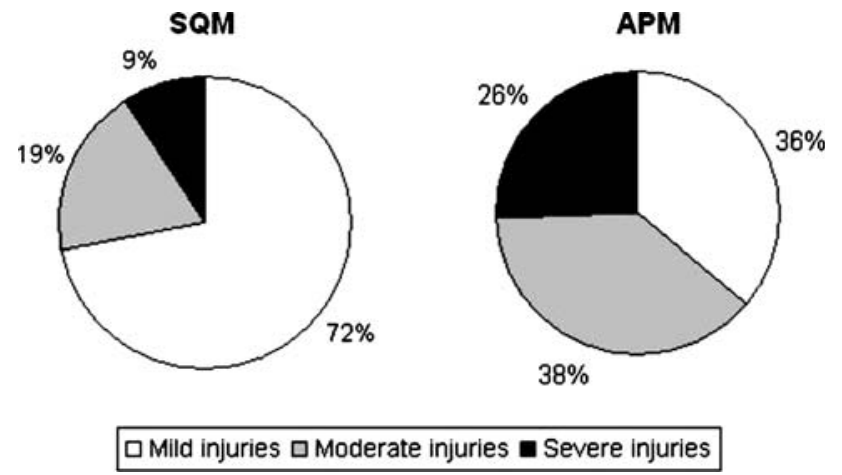

Fig. 1 Percentage of YLDs lost due to mild, moderate and severe injuries, calculated with standard QALY/DALY model (SQM) annual profile model (APM) disability weights

\section{Discussion}

The results showed that, although ranking of both sets of disability weights were concordant, the disability weights obtained with the SQM were consistently higher compared with disability weights obtained with the APM. The difference was relatively large for mild injuries with a rapid course, like eye injury and superficial injury. Application of the SQM disability weights resulted in over three times as many YLDs lost in the first year after the injury compared with the YLD estimation with APM disability weights. For mild injury consequences, this increase was six fold.

Unexpectedly, the VAS values showed the opposite compared with the disability weights obtained with the TTO. With VAS, the population panel valued the health states worse than the patients did. Contrastingly to the TTO, the VAS valuation technique is not choice-based because it does not require the participants to make a tradeoff between something valuable, time in case of the TTO, and health. However, this trade-off provides essential information about the relative (un)desirability of a certain health state compared with other health states. This makes 
the TTO values more appropriate for burden of disease studies.

The commonly used SQM method consists of adding up separately valued periods lived in a certain health state. It assumes that the value of the health state is not affected by the duration of the health state, nor by the sequence of the health states. Furthermore, during the separate periods the health state is assumed to remain constant [5, 6]. To meet the assumption of constant disability, in order to assess the SQM disability weights, we aggregated three periods of equal length valued at fixed points in time that were similar for each of the injury consequences. However, mild injuries with a rapid course consist of a sequence of much shorter periods of different disability levels. As a consequence, assuming constant health for a relatively long period might overestimate the actual impact of the injury consequences.

Reporting bias might also have contributed to the relatively high SQM disability weights. The SQM disability weights were derived from self-reported EQ-5D health status. Self-reported health status, however, might differ from the actual health status. Grootendorst et al. [25] showed that respondents reported more dysfunction in selfcompleted questionnaires compared with interviewadministered responses. A factor that affects the responses to self-reported heath questions are preceding questions [26]. In the questionnaire send to the injury patients, the EQ-5D was preceded by questions regarding the cause and immediate consequences of the sustained injury. This might have caused the injury patients to overemphasize their level of dysfunction at follow-up.

A third aspect that may have affected the SQM disability weights is the baseline information used to calculate the disability weights. In the current study, we used population utility scores as a baseline. However, Cameron et al. [27] showed that pre-existing morbidity in a cohort of injured patients is higher compared with non-injured individuals. These findings of high pre-existing morbidity among injured patients are accorded by Wardle et al. and Polinder et al. [9, 28]. This implies that pre-injury utility scores are in fact lower than utility scores of the population. Therefore, using population utility scores as a baseline instead of pre-injury utility scores results in larger differences in health-related quality of life, and consequently higher SQM disability weights. Additionally, it should be noted that we have used UK population utility scores as a baseline, because EQ-5D population utility scores for The Netherlands are not available. The population health index of the UK, however, might not be comparable to the Dutch population health index.

For the calculation of the APM disability weights, a baseline utility is not required. Moreover, the APM avoids the assumption of constant disability. Rather than aggregating separately valued periods, the APM describes the disability profile of the condition-with generic as well as disease specific information-over the course of 1 year [16]. The APM allows a fixed preference-based threshold to distinguish trivial from minimal relevant disease [29]. As shown by the results, the relatively high values of the SQM disability weights for mild injuries with a rapid course in combination with high incidence result in a larger number of total YLDs, and may lead to policy priority of these mild injuries above severe, less frequently occurring injury consequences. This bias in the application of burden of disease estimates in prioritization issues is avoided by the APM threshold, which implies that only if more than $50 \%$ of participants are willing to trade-off any time, injuries are regarded as relevant [30]. If the cut-off point is not met, the injuries are excluded from the burden of injury calculation. In the current study, two injury groups did not meet the preference-based threshold, namely eye injury and superficial injury. If these two injury groups are excluded from the burden of disease calculations, the total number of YLDs calculated with the set of SQM disability weights will decrease from 54,159 to 30,253 , with $49 \%$ of YLDs lost to mild injuries. The burden of disease calculated with APM disability weights will decrease from 16,947 to 15,133 YLDs, with $22 \%$ lost due to mild injuries.

On the other hand, the APM panel elicited disability weights have several limitations. Firstly, for any new health state, health state valuations have to be obtained by a new panel study in order to derive the disability weights. A second limitation of APM is that, although EQ-5D data from actual patients is used for the description of the health state, the APM disability weights are not able to capture the heterogeneity of the injury consequences as well as SQM disability weights, which are based on individual patient data. For instance, the consequences and duration of an open wound are highly dependent on the size of the wound and the location on the body. The APM health state description of open wound does not capture this variation. Moreover, several studies showed that variation in injury consequences increases with injury severity and duration $[10,31]$. As a result, actual health states of injury patients may differ considerably from the health state descriptions valued with the APM, especially in case of severe injury consequences.

Also, it should be noted that although laypeople may be able to value highly incident injury consequences such as superficial injury and wrist fracture, it may be difficult for them to fully comprehend the impact of less frequently occurring injury consequences on the daily life of a patient living in the particular health state. Inconsistencies in the TTO valuations of severe injury consequences indicate that laypeople are less able to discriminate between severe injury consequences when using the conceptually difficult 
TTO valuation technique [17]. Hence, to calculate YLDs for severe long-term injury consequences, SQM disability weights might be preferable. For health outcome with dynamic or complex patterns, like mild injuries with short duration, the SQM seems to be less appropriate, since it results in relatively high disability weights that seem to overestimate the consequences.

The difference in VAS scores derived from injury patients and the population panel, with patients valuing their own health state as less severe compared, corresponds to the results found in a previous study [32]. A metaanalysis of 33 studies, however, showed that there were no significant differences between patient and non-patient preferences [33]; though it should be noted that the majority of the studies included in the meta-analysis concerned patients with chronic conditions, whereas the current study addressed injuries of mainly short duration. This disparity in duration of health consequences may have affected the patients' valuation of their own health state, since patients adapt to their health states. The effect of adaptation is especially found with chronically ill patients $[34,35]$. The fact that the difference between SQM and APM disability weights is smaller for severe injuries with relatively long duration, like spinal cord injury, compared with mild injuries of short duration may also be due to adaptation to a certain health state.

Nevertheless, the present findings should be interpreted with caution because they are based on two separate datasets that did not allow a direct comparison of the data and because of the aspects mentioned earlier that may have affected the disability weights. The SQM disability weights might be considerably lower if a pre-injury baseline was used rather than a population baseline, and if the time interval to measure the health status of injury patients was more appropriate; although it is impossible to measure the health status of injury patients at the optimal time interval for the numerous consequences of injury. The values of the APM disability weights on the other hand might be higher if they were obtained from a panel of injury patients instead of a population panel, since injury patients have actually experienced the shock of accidentally sustaining an injury and the impact of its consequences on daily life.

We conclude that the approach used to assess disability weights does make a difference, and in their turn yield considerable differences in YLD calculations. The APM seems the preferred method in burden of injury studies that includes mild conditions with a rapid course, since the SQM approach yields relatively high values that may overestimate the impact of the latter. The APM on the other hand may underestimate the impact of injury consequences, especially in case of severe injuries. Nonetheless, in comparing disease burden estimates between diseases or countries differences might be attributed to the methodological choice of disability weights applied in the DALY calculation rather than differences in incidence or prevalence.

Open Access This article is distributed under the terms of the Creative Commons Attribution Noncommercial License which permits any noncommercial use, distribution, and reproduction in any medium, provided the original author(s) and source are credited.

\section{References}

1. Worldbank. (1993). World Development Report 1993: Investing in Health. New York: Oxford University Press.

2. Murray, C. J., Salomon, J. A., \& Mathers, C. D. (2002). Summary measures of population health: Concepts, ethics, measurement and applications. Geneva: World Health Organization.

3. Murray, C. J., \& Acharya, A. K. (1997). Understanding DALYs (disability-adjusted life years). Journal of Health Economics, 16(6), 703-730. doi:10.1016/S0167-6296(97)00004-0.

4. Murray, C. J. L., \& Lopez, A. D. (Eds.). (1996). The global burden of disease: A comprehensive assessment of mortality and disability from diseases, injuries and risk factors in 1990 and projected to 2020. Cambridge: Harvard University Press.

5. Pliskin, J. S., Shepard, D. S., \& Weinstein, M. (1980). Utility functions for life years and health status. Operations Research, 28(1), 206-224. doi:10.1287/opre.28.1.206.

6. Johannesson, M., Jonsson, B., \& Karlsson, G. (1996). Outcome measurement in economic evaluation. Health Economics, 5(4), 279-296. doi:10.1002/(SICI)1099-1050(199607)5:4<279::AIDHEC218>3.0.CO;2-J.

7. Tsuchiya, A., \& Dolan, P. (2005). The QALY model and individual preferences for health states and health profiles over time: A systematic review of the literature. Medical Decision Making, 25(4), 460-467. doi:10.1177/0272989X05276854.

8. Segui-Gomez, M., \& MacKenzie, E. J. (2003). Measuring the public health impact of injuries. Epidemiologic Reviews, 25, 3-19. doi:10.1093/epirev/mxg007.

9. Polinder, S., et al. (2007). Functional outcome at 2.5, 5, 9, and 24 months after injury in The Netherlands. The Journal of Trauma, 62(1), 133-141. doi:10.1097/TA.0b013e31802b71c9.

10. Holtslag, H. R., et al. (2007). Determinants of long-term functional consequences after major trauma. The Journal of Trauma, 62(4), 919-927. doi:10.1097/01.ta.0000224124.47646.62.

11. Tilford, J. M., et al. (2007). Child health-related quality of life following neurocritical care for traumatic brain injury: An analysis of preference-weighted outcomes. Neurocritical Care, 7(1), 64-75. doi:10.1007/s12028-007-0037-5.

12. Brazier, J., Deverill, M., \& Green, C. (1999). A review of the use of health status measures in economic evaluation. Journal of Health Services Research \& Policy, 4(3), 174-184.

13. Kaplan, R. M., \& Anderson, J. P. (1988). A general health policy model: Update and applications. Health Services Research, 23(2), 203-235.

14. The EuroQol Group. (1990). EuroQol—A new facility for the measurement of health-related quality of life. Health Policy (Amsterdam), 16(3), 199-208. doi:10.1016/0168-8510(90)90421-9.

15. Torrance, G. W., Thomas, W. H., \& Sackett, D. L. (1972). A utility maximization model for evaluation of health care programs. Health Services Research, 7(2), 118-133.

16. Essink-Bot, M. L., \& Bonsel, G. J. (2002). How to derive disability weights? In C. J. Murray, A. D. Lopez, \& J. A. Salomon (Eds.), Summary measures of population health: Concepts, ethics, measurement and applications (pp. 449-465). Geneva: World Health Organization. 
17. Haagsma, J. A., et al. (2008). Novel empirical disability weights to assess the burden of non-fatal injury. Injury Prevention, 14(1), 5-10. doi:10.1136/ip.2007.017178

18. Lyons, R. A., et al. (2006). Methodological issues in comparing injury incidence across countries. International Journal of Injury Control and Safety Promotion, 13(2), 63-70. doi:10.1080/174573 00500258682.

19. Brooks, R. (1996). EuroQol: The current state of play. Health Policy (Amsterdam), 37(1), 53-72. doi:10.1016/0168-8510(96) 00822-6.

20. Lamers, L. M., et al. (2005). Measuring the quality of life in economic evaluations: The Dutch EQ-5D tariff. Nederlands Tijdschrift voor Geneeskunde, 149(28), 1574-1578.

21. Kind, P., Hardman, G., \& Macran, S. (1999). UK population norms for EQ-5D. York: Centre of Health Economics, University of York.

22. Stouthard, M. E. A., et al. (2000). Disability weights for diseases: A modified protocol and results for a Western European region. European Journal of Public Health, 10(1), 24-30. doi:10.1093/ eurpub/10.1.24.

23. Polinder, S., et al. (2008). International variation in clinical injury incidence: exploring the performance of indicators based on health care, anatomical and outcome criteria. Accident Analysis and Prevention, 40(1), 182-191. doi:10.1016/j.aap.2007.05.001

24. Meerding, W. J., Mulder, S., \& van Beeck, E. F. (2006). Incidence and costs of injuries in The Netherlands. European Journal of Public Health, 16(3), 272-278. doi:10.1093/eurpub/ck1006.

25. Grootendorst, P. V., Feeny, D. H., \& Furlong, W. (1997). Does it matter whom and how you ask? Inter- and intra-rater agreement in the Ontario health survey. Journal of Clinical Epidemiology, 50(2), 127-135. doi:10.1016/S0895-4356(96)00314-9.

26. Crossley, T. F., \& Kennedy, S. (2002). The reliability of selfassessed health status. Journal of Health Economics, 21(4), 643658. doi:10.1016/S0167-6296(02)00007-3.
27. Cameron, C. M., et al. (2005). Differences in prevalence of preexisting morbidity between injured and non-injured populations. Bulletin of the World Health Organization, 83(5), 345-352.

28. Wardle, T., Driscoll, P., \& Woolford, M. (1995). Medical problems in major trauma. Injury, 26, 137.

29. Bonsel, G. J., Janssen, M. F., \& Birnie, E. (2003). Mild diseases and ailments study (MiDAS). Ziektelastbepaling van 27 vermoedelijk 'lichte' ziekten ten behoeve van rationele beperking van het geneesmiddelenpakket. Amsterdam: Academic Medical Center, University of Amsterdam.

30. Haagsma, J. A., et al. (2008). Disability adjusted life years and minimal disease: Application of a preference-based relevance criterion to rank enteric pathogens. Population Health Metrics, 6(1), 7. doi:10.1186/1478-7954-6-7.

31. Cornwall, R., et al. (2004). Functional outcomes and mortality vary among different types of hip fractures: A function of patient characteristics. Clinical Orthopaedics and Related Research, 425, 64-71. doi:10.1097/01.blo.0000132406.37763.b3.

32. Boyd, N. F., et al. (1990). Whose utilities for decision analysis? Medical Decision Making, 10(1), 58-67. doi:10.1177/0272989X 9001000109.

33. Dolders, M. G., et al. (2006). A meta-analysis demonstrates no significant differences between patient and population preferences. Journal of Clinical Epidemiology, 59(7), 653-664. doi: 10.1016/j.jclinepi.2005.07.020.

34. Adang, E. M., et al. (1997). Quality-of-life ratings in patients with chronic illnesses. Journal of the American Medical Association, 277(13), 1038. doi:10.1001/jama.277.13.1038b.

35. Postulart, D., \& Adang, E. M. (2000). Response shift and adaptation in chronically ill patients. Medical Decision Making, 20(2), 186-193. doi:10.1177/0272989X0002000204. 